\title{
TccP2-mediated subversion of actin dynamics by EPEC 2 - a distinct evolutionary lineage of enteropathogenic Escherichia coli
}

\section{Correspondence \\ Gad Frankel \\ g.frankel@imperial.ac.uk}

Received 14 November 2006

Revised 22 January 2007

Accepted 1 February 2007
Andrew D. Whale, ${ }^{1}$ Rodrigo T. Hernandes, ${ }^{2}$ Tadasuke Ooka, ${ }^{3}$ Lothar Beutin, ${ }^{4}$ Stephanie Schüller, ${ }^{5}$ Junkal Garmendia, ${ }^{6}$ Lynette Crowther, ${ }^{1}$ Mônica A. M. Vieira, ${ }^{2}$ Yoshitoshi Ogura, ${ }^{3}$ Gladys Krause, ${ }^{4}$ Alan D. Phillips, ${ }^{5}$ Tania A. T. Gomes, ${ }^{2}$ Tetsuya Hayashi ${ }^{3}$ and Gad Frankel ${ }^{1}$

${ }^{1}$ Division of Cell and Molecular Biology, Imperial College London, London SW7 2AZ, UK

${ }^{2}$ Departamento de Microbiologia, Imunologia e Parasitologia, Universidade Federal de São Paulo, São Paulo, Brazil

${ }^{3}$ Division of Bioenvironmental Science, Frontier Science Research Center, University of Miyazaki, 5200 Kiyotake, Miyazaki 889-1692, Japan

${ }^{4}$ Nationales Referenzlabor für Escherichia coli, Bundesinstitut für Risikobewertung,

Diedersdorfer Weg 1, D-12277 Berlin, Germany

${ }^{5}$ Centre for Paediatric Gastroenterology, Royal Free and University College Medical School, London, UK

${ }^{6}$ Fundación Caubet-Cimera, Recinto Hospital Joan March, Carretera Soller Km 1207110 Bunyola, Mallorca, Spain

Enteropathogenic Escherichia coli (EPEC) is a major cause of infantile diarrhoea in developing countries. While colonizing the gut mucosa, EPEC triggers extensive actin-polymerization activity at the site of intimate bacterial attachment, which is mediated by avid interaction between the outer-membrane adhesin intimin and the type III secretion system (T3SS) effector Tir. The prevailing dogma is that actin polymerization by EPEC is achieved following tyrosine phosphorylation of Tir, recruitment of Nck and activation of neuronal Wiskott-Aldrich syndrome protein (N-WASP). In closely related enterohaemorrhagic E. coli (EHEC) 0157 : H7, actin polymerization is triggered following recruitment of the T3SS effector TccP/EspF (instead of Nck) and local activation of N-WASP. In addition to tccP, typical EHEC O157 : H7 harbour a pseudogene (tccP2). However, it has recently been found that atypical, sorbitol-fermenting EHEC 0157 carries functional tcc $P$ and $t c c P 2$ alleles. Interestingly, intact $t c c P 2$ has been identified in the incomplete genome sequence of the prototype EPEC strain B171 (serotype $\mathrm{O} 111$ : $\mathrm{H}-$ ), but it is missing from another prototype EPEC strain E2348/69 (O127 : H7). E2348/69 and B171 belong to two distinct evolutionary lineages of EPEC, termed EPEC 1 and EPEC 2, respectively. Here, it is reported that while both EPEC 1 and EPEC 2 triggered actin polymerization via the Nck pathway, tccP2 was found in 26 of 27 (96.2\%) strains belonging to EPEC 2, and in none of the 34 strains belonging to EPEC 1. It was shown that TccP2 was: (i) translocated by the locus of enterocyte effacement-encoded T3SS; (ii) localized at the tip of the EPEC 2-induced actin-rich pedestals in infected HeLa cells and human intestinal in vitro organ cultures ex vivo; and (iii) essential for actin polymerization in infected Nck-/- cells. Therefore, unlike strains belonging to EPEC 1, strains belonging to EPEC 2 can trigger actin polymerization using both Nck and TccP2 actin-polymerization signalling cascades.

Abbreviations: A/E, attaching and effacing; BFP, bundle-forming pilus; EAF, enteropathogenic Escherichia coli adherence factor; EHEC, enterohaemorrhagic Escherichia coli; EPEC, enteropathogenic Escherichia coli; FAS, fluorescent actin staining; HA, haemagglutinin; IVOC, in vitro organ culture; LEE, locus of enterocyte effacement; MEF, mouse embryo fibroblast; PRR, proline-rich repeat; N-WASP, neuronal Wiskott-Aldrich syndrome protein; T3SS, type III secretion system. 


\section{INTRODUCTION}

Enteropathogenic Escherichia coli (EPEC) is the leading cause of childhood diarrhoea in developing countries (reviewed by Chen \& Frankel, 2005). EPEC strains belong to a large number of $\mathrm{O}: \mathrm{H}$ serotypes (Trabulsi et al., 2002) and are divided into typical and atypical categories (Kaper, 1996). Typical EPEC are defined by the presence of the locus of enterocyte effacement (LEE) pathogenicity island (McDaniel et al., 1995), and the EPEC adherence factor (EAF) plasmid (Baldini et al., 1983) that carries the transcriptional regulator locus per (Mellies et al., 1999), and encodes the type IV bundle-forming pilus (BFP) (Girón et al., 1991). The most common O serogroups of typical EPEC are O55, O111, O119, O127 and O142. Typical EPEC are further divided into two distinct evolutionary lineages known as EPEC 1 and EPEC 2 (Orskov et al., 1990). The EPEC 1 branch is characterized by expression of flagella serotypes H6 and H34 (Whittam et al., 1993), the presence of a complete tra region on the EAF plasmid (Brinkley et al., 2006), and a distinctive antigenic type $\alpha$ of the outer-membrane adhesin intimin (Adu-Bobie et al., 1998), while the EPEC 2 branch expresses the flagella serotype $\mathrm{H} 2$ (or $\mathrm{H}-$ ) (Whittam et al., 1993), lacks the tra region (Brinkley et al., 2006), and expresses the intimin subtype $\beta$ (Adu-Bobie et al., 1998).

Enterohaemorrhagic E. coli (EHEC) is a subgroup of Verocytotoxin (VT)-producing E. coli (VTEC) that can cause bloody diarrhoea, haemorrhagic colitis and haemolytic-uraemic syndrome (HUS). E. coli O157 : H7 is the most common and virulent EHEC serotype that is implicated worldwide in human disease (reviewed by Karch et al., 2005).

EPEC and EHEC colonize the gut mucosa via attaching and effacing (A/E) lesion formation, which is characterized by intimate attachment of the pathogen to the host intestinal epithelium, localized effacement of the brush border microvilli (Knutton et al., 1987), and localized actin polymerization. A/E lesion formation and actin polymerization are dependent on the LEE-encoded type III secretion system (T3SS) (Jarvis et al., 1995), the adhesin intimin (Jerse et al., 1990), and translocation of the effector protein Tir (translocated intimin receptor) (Kenny et al., 1997). Once translocated, Tir is integrated into the hostcell plasma membrane, in which it adopts a hairpin loop topology (Hartland et al., 1999), with the extracellular loop presented above the plasma membrane acting as a receptor for the bacterial adhesin intimin (reviewed by Frankel et al., 2001). Intimin-mediated clustering of Tir (Campellone et al., 2004b) leads to accretion of several cytoskeletal proteins to the intracellular amino- and carboxy-terminal Tir domains, linking the extracellular bacterium to the host-cell cytoskeleton (Goosney et al., 2001) and triggering actin remodelling into pedestal-like structures. Tir of the prototype EPEC O127 : H6 strain E2348/69, which belongs to EPEC 1, harbours a tyrosine residue Y474 that is present in the context of a consensus binding site for the mammalian adaptor protein Nck $\left(\mathrm{Y}_{\mathrm{P}} \mathrm{DEP} / \mathrm{D} / \mathrm{V}\right)$ (Campellone et al., 2002; Gruenheid et al., 2001). Tyrosine phosphorylation of $\operatorname{Tir}\left[\operatorname{Tir}_{(\mathrm{Y}-\mathrm{P})}\right]$ by host-cell kinases (Phillips et al., 2004; Swimm et al., 2004) recruits Nck to the site of bacterial attachment, which in turn binds the actin nucleation-promoting factor neuronal WiskottAldrich syndrome protein (N-WASP), initiating actin polymerization via activation of the actin-related protein 2/3 (Arp2/3) complex (Lommel et al., 2001). In contrast, the equivalent position in Tir EHEC O157 : H7 is occupied by serine $\left[\operatorname{Tir}_{(\mathrm{S})}\right]$, and as such, Nck is not involved in actin polymerization by EHEC O157 : H7 (Gruenheid et al., 2001). Instead, EHEC O157:H7 requires a second bacterial T3SS effector protein, TccP (Tir-cytoskeleton coupling protein; also termed $\mathrm{EspF}_{\mathrm{U}}$, because it shares $35 \%$ identity with the T3SS effector EspF), which binds, recruits and activates N-WASP to trigger localized actin polymerization (Campellone et al., 2004a; Garmendia et al., 2004). The minimal region of Tir EHEC O157 that is needed for recruitment of $\mathrm{TccP}$ and induction of actin polymerization is a 12 aa motif at the $\mathrm{C}$ terminus (Campellone et al., 2006; Allen-Vercoe et al., 2006). This 12 aa motif is conserved in Tir EPEC O127 : H6, and has been implicated in an Nck-independent actin-remodelling pathway during infection with O127 : H6 EPEC (Campellone and Leong, 2005). Importantly, TccP does not bind Tir directly (Campellone et al., 2004a; Garmendia et al., 2004).

tccP is carried on prophage CP-933U/Sp14 (Campellone et al., 2004a; Garmendia et al., 2004) and consists of a unique 80 aa $\mathrm{N}$-terminal region (involved in protein translocation) and several almost identical 47 aa prolinerich repeats (PRRs) (Garmendia et al., 2006). In a recent survey of clinical and environmental strains, $t c c P$ was found in $100 \%$ of EHEC O157 : H7 and in a minority of EPEC and non-O157 EHEC strains (Garmendia et al., 2005). Of particular importance is the fact that in $t c c P$ positive EPEC, Tir is tyrosine-phosphorylated $\left[\operatorname{Tir}_{(\mathrm{Y}-\mathrm{P})}\right]$ and simultaneously recruits $\mathrm{Nck}$ and TccP under attached bacteria during infection of cultured epithelial cells (Whale et al., 2006).

EHEC O157 : H7 strains Sakai and EDL933 also contain pseudo $t c c P$ genes (ECs1126 and Z1385, respectively, which have also been referred to as $e s p F_{M}$ by Campellone et al. 2004a), which are carried on prophage Sp4/CP-933M. A deletion of a single (T/A) base pair at position 28 introduces a translational frameshift and a premature stop codon. However, we have recently found that $\beta$-glucuronidase-positive/sorbitol-fermenting strains of EHEC O157 harbour an intact ECs1126 gene, in addition to tccP (Ogura et al., 2007). In order to discriminate between the tccP alleles, we named ECs1126, which is carried on prophage Sp4/CP-933M, tccP2. The aim of this study was to determine the distribution and function of $t c c P 2$ in typical EPEC belonging to serogroups O55, O84, O111, O114, $\mathrm{O} 127$ and $\mathrm{O} 142$, which we have previously reported to be tccP gene-negative (Garmendia et al., 2005) O119: H6. 


\section{METHODS}

PCR amplification of tccP2 and tir and colony blot hybridization. Clinical EPEC strains are listed in Table 1. Conventional PCR was used to amplify tccP2 with gene-specific tccP2-F and tccP2-R primers. Forward, gene-specific primers tirY474-F and tirS478-F were used together with a conserved reverse primer (tir-R) to discriminate between $\operatorname{tir}_{\mathrm{E} 2348 / 68}$ and $t i r_{\text {Sakai }}$ gene types [that encode $\operatorname{Tir}_{(\mathrm{Y}-\mathrm{P})}$ and $\operatorname{Tir}_{(\mathrm{S})}$, respectively]; primers used in this study are listed in Table 2. Colony blot hybridization was performed using standard protocols and a $\operatorname{tccp} 2$ gene probe.

Locus-specific sequencing. The tccP2 genes and their $5^{\prime}-$ and $3^{\prime}-$ flanking regions were amplified using a Blend taq PCR amplification Kit (Toyobo) and the PCR primer pairs tccP2-SFb and tccP2-SRb (Table 2). Direct sequencing of the PCR products was done using the primers used for amplification and an ABI PRISM 3100 automated sequencer. When necessary, internal sequencing primers were used.

Preparation of TccP rabbit antiserum. A PCR fragment encoding a truncated $\mathrm{TccP} \mathrm{EDL933}_{\mathrm{E}}$ derivative comprising the unique $\mathrm{N}$ terminus and two PRRs $\left(\operatorname{Tcc}_{\mathrm{N} 2 \mathrm{R}}\right)$ was cloned into pET28-a as described previously (Ogura et al., 2007); $\mathrm{TccP}_{\mathrm{N} 2 \mathrm{R}}$-His was purified as described by Hartland et al. (1999), and polyclonal $\mathrm{TccP}_{\mathrm{N} 2 \mathrm{R}}-\mathrm{His}$ antiserum was produced in rabbits at Covalab.

Preparation of protein samples for detection of TccP and TccP2 by Western blotting. Protein preparations from whole-cell extracts were dissolved in protein-denaturing buffer before PAGE and Western blotting. TccP was detected using a rabbit polyclonal antiTccP primary antibody (diluted $1: 1000$ ) and porcine anti-rabbit IgG-horseradish peroxidase conjugate secondary antibody (Dako).

Bacterial strains, growth conditions and plasmids. Bacterial strains used for the functional analysis are listed in Table 3. Bacteria were grown at $37^{\circ} \mathrm{C}$, with aeration in Luria-Bertani (LB) medium or Dulbecco's Modified Eagle's Medium (DMEM), supplemented with ampicillin $\left(100 \mu \mathrm{g} \mathrm{ml}^{-1}\right)$ or kanamycin $\left(50 \mu \mathrm{g} \mathrm{ml}^{-1}\right)$, or both, when necessary. E. coli B171 4 tccP2 mutant was constructed using the $\lambda$ Red recombinase method (Datsenko \& Wanner, 2000). Disruption of $t c c P 2$ was performed with a kanamycin-resistance cassette generated with primers $\mathrm{B} 171 \mathrm{tcc}-\mathrm{P} 1$ and $\mathrm{B} 171 \mathrm{tccP}-\mathrm{R} 1$ using $\mathrm{pKD} 4$ as template. Purified PCR product was electroporated into E. coli B171(pKD46). Clones were grown on LB medium + kanamycin to select for kanamycin $(\Delta t c c P 2)$ resistance. pKD46 was cured from the resulting strains by growth at $43{ }^{\circ} \mathrm{C}$. Primers flanking the deleted region and inside the kanamycin-resistance cassette were used in PCR to verify the deletion (primer pairs $\mathrm{K} 1$ and tccP2-F, and $\mathrm{K} 2$ and tccP2-R).

pICC364 is a derivative of pCX340 (Charpentier \& Oswald, 2004). An 894 bp fragment containing tccP2 was amplified by PCR from B171 genomic DNA using primers pCX-B171tccP-F1 and pCX-B171tccPR1. The 915 bp PCR product, containing terminal EcoRI and NotI sites, was digested and ligated into pCX340, generating pICC364.

pICC365 and pICC366 are derivatives of pSA10 (Schlosser-Silverman et al., 2000), a vector containing multiple cloning sites downstream of the tac promoter. An $894 \mathrm{bp}$ fragment containing tccP2 was amplified by PCR from B171 genomic DNA using primers pkk-tccP2-F1 and pkk-tccP2-R1. A 1176 bp fragment containing tccP2 was amplified by PCR from EPEC O111: H2 strain ICC215 genomic DNA using primers pkk-tccP2-F1 and pkk-tccP2-R1. The $970 \mathrm{bp}$ (B171 tccP2) and 1252 (ICC215 tccP2) bp PCR products, containing terminal EcoRI and PstI sites, were digested and ligated into pSA10, generating pICC365 and pICC366, respectively.

Antibodies and reagents. Anti-E. coli O157 : $\mathrm{H} 7$ goat polyclonal antibody (Fitzgerald Industries International) was diluted 1:500. EPEC ICC199 and B171 strains were detected with rabbit polyclonal Int280 $\beta$ antiserum (Adu-Bobie et al., 1998), and EPEC E2348/69 was detected with rabbit polyclonal Int280 $\alpha$ antiserum (Adu-Bobie et al., 1998), both diluted $1: 500$. Rabbit polyclonal $\operatorname{Tir}_{\text {EPEC }}$ antiserum was diluted 1:500. Phosphotyrosine and Nck were detected using monoclonal mouse anti-phosphotyrosine clone 4G10 (Sigma) and rabbit polyclonal anti-Nck (Upstate) antibodies, diluted 1:250 and $1: 150$, respectively. Mouse anti-haemagglutinin (HA) mAb HA.11 (Covance) was diluted $1: 200$. Rhodamine-, Alexa 633- and Oregon Green-conjugated phalloidin (Invitrogen) were used at dilutions of $1: 500,1: 500$ and $1: 100$, respectively. Cy5-conjugated donkey anti-goat, rhodamine-conjugated donkey anti-goat, donkey antirabbit and Cy2-conjugated donkey anti-mouse antibodies (Jackson Immunoresearch Laboratories) were diluted $1: 200$. Samples were analysed using either a Zeiss LSM510 confocal laser scanning

Table 1. Distribution of $t c c P 2$ among clinical EPEC 1 and EPEC 2 isolates

ND, Not determined.

\begin{tabular}{|c|c|c|c|}
\hline Serotype & No. of strains & tccP2 & Tir type \\
\hline \multicolumn{4}{|l|}{ EPEC 1} \\
\hline O55 : H6 & 10 & - & $\mathrm{Y}-\mathrm{P}(5)^{\star}, \mathrm{ND}(5)$ \\
\hline O86 : H34 & 4 & - & Y-P (3), ND (1) \\
\hline O127 : H6 & 5 & - & Y-P (3), ND (2) \\
\hline O142 : H6 & 6 & - & Y-P (4), ND (2) \\
\hline O142: H34 & 3 & - & Y-P \\
\hline \multicolumn{4}{|l|}{ EPEC 2} \\
\hline $\mathrm{O} 111: \mathrm{H}-$ & 8 & $+[1150 \mathrm{bp}] \dagger(6)^{*},+[700 \mathrm{bp}](1),-(1)$ & Y-P \\
\hline $\mathrm{O} 111: \mathrm{H} 2$ & 18 & $+[1150 \mathrm{bp}](14),+[1000 \mathrm{bp}](3),+[1800 \mathrm{bp}](1)$ & Y-P \\
\hline $\mathrm{O} 114: \mathrm{H} 2$ & 1 & $+[1150 \mathrm{bp}]$ & Y-P \\
\hline \multicolumn{4}{|c|}{ EPEC non-1 non-2 } \\
\hline O119: H6‡ & 6 & - & Y-P \\
\hline
\end{tabular}

${ }^{*}$ The number of strains is given in parentheses.

$\dagger$ The size of $t c c P 2$ amplicons is indicated in brackets.

\$ccP-positive strain. 
Table 2. Primers used in this study

\begin{tabular}{|ll|}
\hline Primer & \multicolumn{1}{c|}{ Nucleotide sequence $\left(\mathbf{5}^{\prime} \mathbf{-} \mathbf{3}^{\prime}\right)$} \\
\hline tccP2-F & ATGATAAATAGCATTAATTCTTT \\
tccP2-R & TCACGAGCGCTTAGATGTATTAAT \\
tirY474-F & CATATTTATGATGAGGTCGCTC \\
tirS478-F & TCTGTTCAGAATATGGGGAATA \\
tir-R & TAAAAGTTCAGATCTTGATGACAT \\
tccP2-SFb & GGTAGATTTCATGCAAACGG \\
tccP2-SRb & AATAACCGGTAACTGTCAGGTC \\
B171tccP-F1 & CACAGCACAAAAGCACACCTAACACGGTAAAAACCAGCTCACCTCTTTC- \\
& TCGTGTAGGCTGGAGCTGCTTC \\
B171tccP-R1 & GAGGTCTTGATTGTTCATTTTGTACTGGCGGCGTTGGCGGAGGCCAGTT- \\
k1 & ACATATGAATATCCTCCTTAG \\
k2 & CAGTCATAGCCGAATAGCCT \\
pkk-tccP2-F1 & CGGTGCCCTGAATGAACTGC \\
pkk-tccP2-R1 & CCGGAATTCATGATAAATAGCATTAATTCTTTT \\
& AAAACTGCAGTCAAGCGTAGTCTGGGACGTCGTATGGGTAAGCGT- \\
pCX-B171tccP-F1 & AGTCTGGGACGTCGTATGGGTACGAGCGCTTAGATGTATTAATGCC \\
pCX-B171tccP-R1 & GGGTTTCATATGATAAATAGCATTAATTCTTT \\
& CCGGAATTCTCCGAGCGCTTAGATGTATTAATG \\
\hline
\end{tabular}

microscope or a Zeiss Axio Imager fluorescence microscope. Infected cells were fixed and fluorescent actin staining (FAS) used to determine the ability of each strain to trigger the formation of actin-rich pedestals. The efficiency of pedestal formation was quantified by measuring the percentage of adherent bacteria that associated with intense actin accretion. Randomly chosen cells harbouring discrete regions of 2-30 bacteria per cell were examined for each strain, and 300 bacteria, 50 per coverslip, from two or three independent infections carried out in duplicate, were counted in a blinded fashion. Statistical differences between groups were determined by ANOVA. To quantify the adherence of strains B171 and $\mathrm{B} 171 \Delta t c c P 2$ to HeLa cells, the percentage of cells with at least three adhering bacteria was counted. For each strain, 200 randomly chosen cells from two independent infections carried out in duplicate were examined.

Cell culture and infection. HeLa cells (clone HtTA1) and mouse embryo fibroblast (MEF) N-WASP ${ }^{-1-}$, N-WASP ${ }^{+1+}$ (a kind gift from S. Snapper, Harvard Medical School, Boston, MA, USA), Nck1-/Nck2- and Nck1 +/Nck2 + cell lines were grown in DMEM supplemented with 10 or $15 \%$ fetal calf serum (FCS), respectively, containing $2 \mathrm{mM}$ glutamine at $37{ }^{\circ} \mathrm{C}$ in $5 \% \mathrm{CO}_{2}$. Cells were seeded onto glass coverslips ( $12 \mathrm{~mm}$ diameter) in 24 -well plates at a density of $5 \times 10^{4}$ cells per well, $24 \mathrm{~h}$ before infection. Bacterial cultures grown in LB medium for $8 \mathrm{~h}$ were diluted $1: 500$ into DMEM and incubated as static cultures at $37{ }^{\circ} \mathrm{C}$ in $5 \% \mathrm{CO}_{2}$ overnight, and were used to

Table 3. E. coli strains and plasmids

\begin{tabular}{|c|c|c|}
\hline Strain or plasmid & Description & Source \\
\hline \multicolumn{3}{|l|}{ Strains } \\
\hline EDL933 & EHEC O157 : H7 stx ${ }^{-}$ & ATCC* \\
\hline E2348/69 & Wild-type EPEC 1 O127 : H6 & Levine et al. (1978) \\
\hline ICC192 & $\Delta e s c N:: \mathrm{Km}$ in E. coli $\mathrm{O} 127: \mathrm{H} 6 \mathrm{E} 2348 / 69$ & Garmendia et al. (2004) \\
\hline ICC199 & Human clinical isolate E. coli $\mathrm{O} 119$ : $\mathrm{H} 6 t c c P^{+}$(non-1 non-2 EPEC) & Whale et al. (2006) \\
\hline ICC215 & Human clinical isolate E. coli $\mathrm{O} 111: \mathrm{H} 2 t c c P 2^{+}$(EPEC 2) & This study \\
\hline B171 & Wild-type EPEC $2 \mathrm{O} 111: \mathrm{H}-t c c P 2^{+}$ & Riley et al. (1987) \\
\hline ICC216 & $\Delta t c c P 2:: \mathrm{Km}$ in E. coli $\mathrm{O} 111: \mathrm{H}-$ strain $\mathrm{B} 171$ & This study \\
\hline ICC185 & $\Delta t c c P:: \mathrm{Km}$ in E. coli $\mathrm{O} 157: \mathrm{H} 7 \mathrm{EDL} 933$ & Garmendia et al. (2004) \\
\hline \multicolumn{3}{|l|}{ Plasmids } \\
\hline pCX340 & pBR322 derivative used to generate blaM gene fusions & Charpentier \& Oswald (2004) \\
\hline pICC364 & pCX340 derivative encoding TccP2_B171 fused to TEM-1 & This study \\
\hline pKD46 & Helper plasmid & Datsenko \& Wanner (2000) \\
\hline pSA10 & pKK177-3 derivative containing $l a c^{q}$ & Schlosser-Silverman et al. (2000) \\
\hline pICC281 & pSA10 derivative encoding TccP_O157-FLAG fusion protein & Garmendia et al. (2004) \\
\hline pICC365 & pSA10 derivative encoding TccP2_B171-HA & This study \\
\hline pICC366 & pSA10 derivative encoding TccP2_ICC215-HA & This study \\
\hline
\end{tabular}

^American Type Culture Collection. 
infect cells for $3 \mathrm{~h}$ (EPEC strains) or $5 \mathrm{~h}$ (EHEC strains). For immunofluorescence, cell monolayers were fixed in $3.7 \%$ parafor-

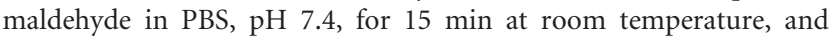
washed three times with PBS. Antibodies were diluted in $10 \%$ horse serum, $0.1 \%$ saponin in PBS. Coverslips were washed twice in PBS containing $0.1 \%$ saponin, incubated for $30 \mathrm{~min}$ with primary antibodies, washed twice with $0.1 \%$ saponin in PBS, and incubated for $30 \mathrm{~min}$ with secondary antibodies. Coverslips were washed twice in $0.1 \%$ saponin in PBS, once in PBS and once in water, and mounted with Aqua-Poly/Mount (Polysciences).

Effector-protein translocation assay. Overnight EPEC cultures were diluted $1: 100$ into $5 \mathrm{ml}$ DMEM containing $10 \%$ FCS and $2 \mathrm{mM}$ glutamine, and incubated at $37{ }^{\circ} \mathrm{C}$ in $5 \% \mathrm{CO}_{2}$ for $3.5 \mathrm{~h}$ (preactivation). HeLa cells were infected with the preactivated bacteria for $30 \mathrm{~min}$ before IPTG was added at a final concentration of $1 \mathrm{mM}$, and the infection was allowed to proceed for an additional $1 \mathrm{~h}$. Cell monolayers were washed three times with PBS, and covered with $100 \mu \mathrm{l} \mathrm{PBS}$ and $25 \mu \mathrm{l} 6 \times$ concentrated $\beta$-lactamase substrate CCF2/AM (Charpentier and Oswald, 2004). The cells were incubated for $2.5 \mathrm{~h}$ at room temperature, washed three times with PBS, covered with coverslides, and live cells were observed under a Nikon Eclipse E600 fluorescence microscope using a UV-2A filter set $(330-380 \mathrm{~nm}$ excitation). Pictures were taken under a Nikon digital camera DXM1200.

Human intestinal in vitro organ culture (IVOC). Tissue was obtained with fully informed parental consent and local ethical committee approval, using grasp forceps during routine endoscopic investigation of intestinal disorders. Small intestinal mucosal biopsies, which appeared macroscopically normal, were taken for organculture experiments as described by Hicks et al. (1998). Adherence of strains $\mathrm{B} 171$ and $\mathrm{B} 171 \Delta t c c P 2$ was examined using tissue from two patients (aged 159 and 181 months) for scanning electron microscopy, and two further cases (aged 194 and 195 months) for cryosectioning and immunostaining. In each experiment, a noninfected sample was included to exclude endogenous bacterial adhesion. Samples for scanning electron microscopy were processed as described by Hicks et al. (1998). For immunofluorescence, samples were embedded in OCT compound (Sakura), snap-frozen in liquid nitrogen, and stored at $-70{ }^{\circ} \mathrm{C}$ until use. Serial sections of $8 \mu \mathrm{m}$ were cut with an MTE cryostat (SLEE Technik), picked up on poly-Llysine-coated slides, and air-dried. Tissue sections were fixed in formalin for $10 \mathrm{~min}$, and blocked with $0.5 \%$ BSA and $2 \%$ normal goat serum in PBS for $20 \mathrm{~min}$ at room temperature. Slides were incubated in primary antibody (rabbit anti-Nck, rabbit anti-TccP) for $60 \mathrm{~min}$ at room temperature, and washed and incubated in Alexa Fluor 488-conjugated goat anti-rabbit IgG (Molecular Probes) for 30 min. Counterstaining of bacteria and cell nuclei was performed using propidium iodide (Sigma). Epithelial cells were stained with mouse anti-cytokeratin (Dako) and Alexa Fluor 647-conjugated goat antimouse IgG (Molecular Probes). Sections were analysed with a Radiance 2100 confocal laser scanning microscope equipped with an argon-krypton laser and a red diode (Bio-Rad).

\section{RESULTS}

\section{tccP2 is absent from EPEC 1 and associated with the EPEC 2 lineage}

We employed conventional PCR to amplify tccP2 (Fig. 1a) using DNA from typical EPEC isolates as a template and gene-specific primers. $t c c P 2$ was found in 26 of 27 (96.2\%) strains belonging to EPEC 2, but in none of the 34 EPEC 1 isolates (Table 1) and O119: H6, which is evolutionarily distinct from EPEC 1 and EPEC 2 (Whittam \& McGraw, 1996), and which we have previously shown encodes biologically active TccP (Whale et al., 2006). The tccP2 amplicons varied in length from 700 to 1800 bp (Table 1). We further confirmed the absence of $t c c P$ or $t c c P 2$ in 14 randomly chosen, PCR-negative isolates by colony blot hybridization (data not shown).

Locus-specific PCR was used to amplify and sequence the tccP2 locus of representative strains, confirming the presence of an intact ORF. Amino acid sequence alignment of the TccP2 polypeptides revealed that other than differences in the number of PRRs, which ranged from three to 10 , the proteins shared a high level of sequence similarity (Fig. 1b). Moreover, the PRRs of TccP2 overlapped almost exactly with those of TccP of EHEC O157 : H7 and EPEC O119 : H6 (Fig. 1b).

\section{TccP2 is a translocated effector protein}

Antiserum raised against TccP is cross-reactive with TccP2 due to the sequence identity of the PRRs. Using the antiserum to analyse whole-cell extracts of $t c c P$-negative/ tccP2-positive EPEC 2 lineage strains B171 (O111: H-) and ICC215 (O111 : H2), and $t c c P$-positive/tccP2-negative strains EHEC EDL933 (O157 : H7) and EPEC 'non-1 non-2 lineage' ICC199 (O119: H6) as controls, revealed reactive bands of different sizes that correlated with differences in the number of PRRs; no band was detected in the tccP-negative/tccP2-negative EPEC 1 strain E2348/69 (O127 : H6) or in EDL933 $\Delta t c c P$ (Fig. 2a). These results show that $t c c P 2$ is expressed in EPEC 2 strains.

TccP2 of EPEC 2 strain $\mathrm{B} 171$ is $77 \%$ identical $(87 \%$ similar) to TccP of EHEC O157 : H7. However, while the PRRs were nearly identical, the $\mathrm{N}$ termini showed only $40 \%$ identity (Fig. 1b). Since this region of TccP contains the critical translocation signal (Garmendia et al., 2006), we used the TEM-1 $\beta$-lactamase-based translocation assay (Charpentier \& Oswald, 2004) to determine if TccP2_B171 was translocated into the host cell. Translocation was detected directly within living host cells by using the fluorescent $\beta$-lactamase substrate CCF2/AM. HeLa cells were infected with wild-type and T3SS-deficient $\Delta e s c N$ mutant EPEC strains carrying pICC364, a plasmid that encodes a translational fusion of TccP2_B171 to TEM-1. Expression of the fusion protein in these strains was verified by Western blot (data not shown), and translocation of the protein into infected HeLa cells was analysed (Fig. 2b). Uninfected HeLa cells or cells infected with E2348/69(pCX340) (negative control, empty vector) appeared green, indicating the absence of TEM-1 activity (Fig. 2b, i). Cells infected with E2348/69(pICC364) expressing TccP2_B171-TEM-1 appeared blue (Fig. 2b, ii), indicating that TEM-1 was translocated into the host cells. Moreover, this translocation was fully dependent on a functional T3SS, given that it was not observed when HeLa cells were infected with E2348/69 $\Delta e s c N$ (pICC364) (Fig. 2b, 
(a)
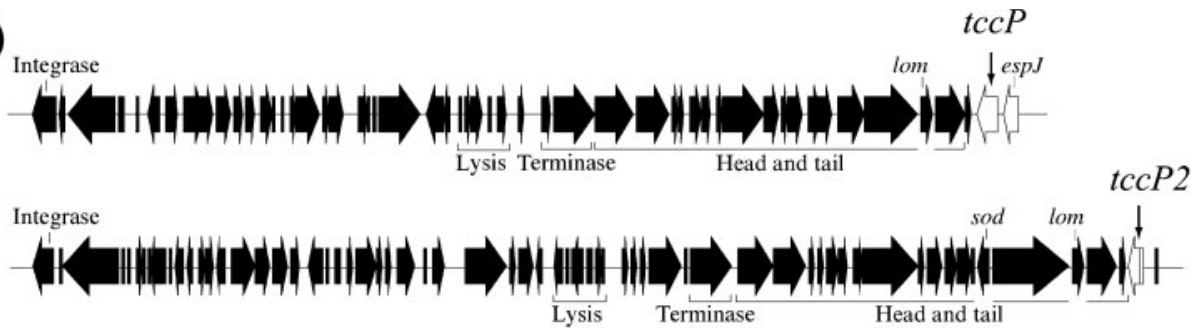

(b)

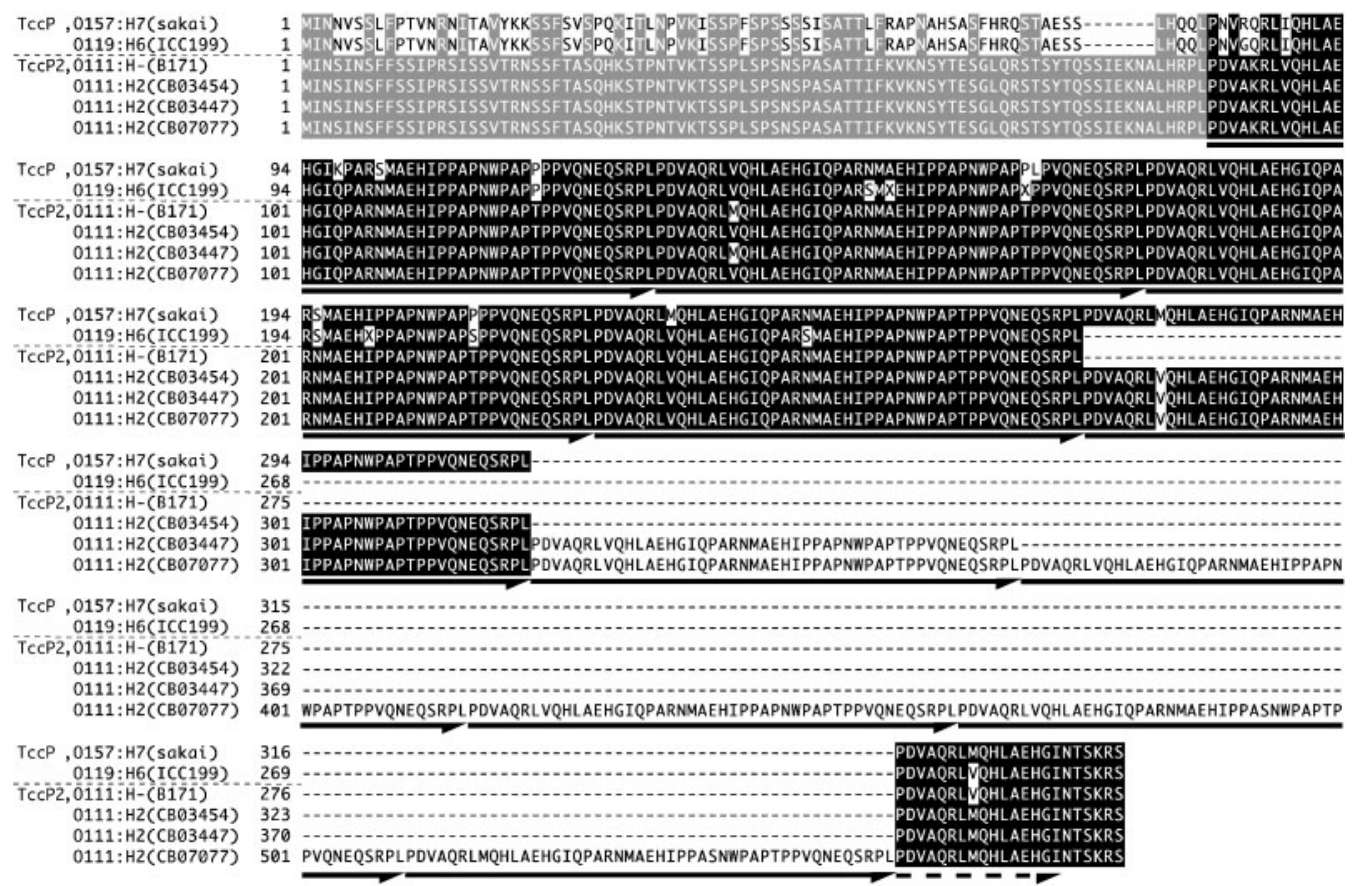

Fig. 1. (a) Schematic representation of the genomic localization of $t c c P$ and $E C s 1126$ (renamed tccP2) in EHEC O157 : H7 (strain Sakai). tccP is located on prophage Sp14 (top) and tccP2 on Sp4 (bottom). (b) Multiple sequence alignment of TccP of EHEC O157 : H7 (strain Sakai) and EPEC O119 : H6 (strain ICC199), and TccP2 of EPEC O111: H- (strain B171) and EPEC 0111 : $\mathrm{H} 2$ (strains CB03454, CB03447 and CB07077). The unique $\mathrm{N}$ terminus is shaded grey and the PRRs are shaded black. The complete unit of a PRR and a partial C-terminal repeat are indicated by arrows and a dashed arrow, respectively. The TccP sequence of ICC199 was taken from Whale et al. (2006) (accession no. DQ206456), and that for TccP2 of B171 from its unfinished genome sequence (AAJX01000044.1). Note that the tccP2 gene is not annotated in the B171 genome sequence.

iii). These results show that TccP2 is an effector protein translocated into host cells by the LEE-encoded T3SS.

\section{B171 triggers Nck-independent actin polymerization}

Activation of the phospho-Tir $[\operatorname{Tir}(\mathrm{P})]-\mathrm{Nck}$ actin-remodelling pathway is necessary for induction of actin-rich pedestals during infection with EPEC 1 strain E2348/69 (O127 : H7) (Campellone et al., 2004b). In contrast, Nck is not recruited to the site of bacterial adhesion during infection with EHEC O157 : H7 (EDL933) (Gruenheid et al., 2001), at which Tir and TccP are necessary for A/E lesion formation (Campellone et al., 2004a; Garmendia et al., 2004). In order to characterize TccP2-positive EPEC 2, HeLa cells were infected with strains B171 and ICC215. As controls, HeLa cells were infected with strains E2348/69 and EDL933. Immunostaining revealed tyrosine phosphorylation (a signal that previous studies have shown to correspond to $\operatorname{Tir}_{(\mathrm{Y}-\mathrm{P})}$; Kenny et al., 1997) below adherent E2348/69, B171 and ICC215, but not EDL933 (Fig. 3a).

A feature of strains harbouring a functional $t c c P$ gene is their ability to efficiently trigger actin-pedestal formation on fibroblast cells lacking Nck (Gruenheid et al., 2001; Campellone et al., 2004a; Whale et al., 2006). Accordingly, we compared the ability of EPEC 2, EPEC 1 and EHEC $\mathrm{O} 157$ : H7 to induce actin-pedestal assembly during infection of Nck1-/Nck2- and Nck1+/Nck2 + fibroblasts. 
(a)

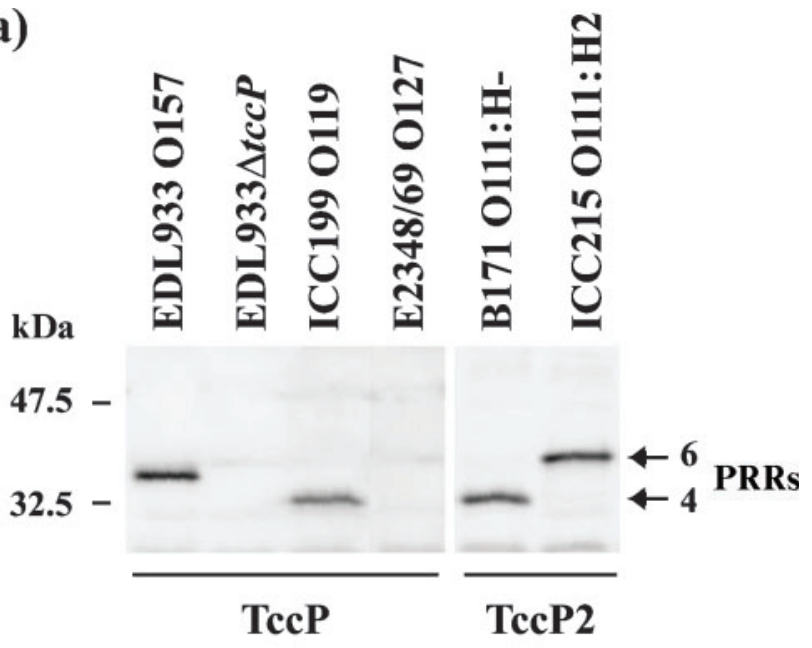

(b)
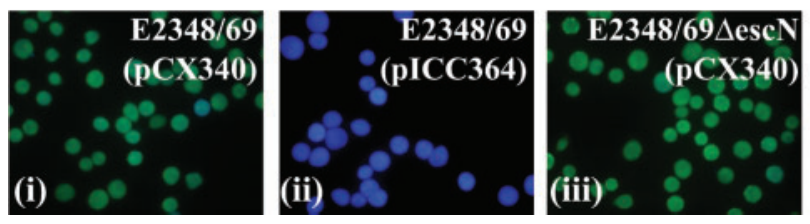

Fig. 2. (a) TccP was detected with $\mathrm{TccP}$ antiserum in bacterial whole-cell lysates of EHEC EDL933 and EPEC ICC199, but not EDL933 $\Delta t c c P$ or EPEC E2348/69. TccP2 was also detected using TccP antiserum in lysates of EPEC $0111: \mathrm{H} 2$ strain ICC215 and EPEC O111 : NM strain B171. (b) TccP2 is a T3SStranslocated effector. Translocation of the EPEC B171 effector protein TccP2 into live HeLa cells using TEM-1 fusion and fluorescence microscopy is shown. HeLa cells were infected with wild-type EPEC E2348/69 carrying pCX340 (negative control) (i), and E2384/69 (ii) and E2348/69 $\Delta$ escN (iii) strains expressing TccP2_B171-TEM fusion protein. $\beta$-Lactamase activity in HeLa cells was revealed by the blue fluorescence emitted by the cleaved CCF2 product (cells infected with E2348/69 expressing TccP2TEM), whereas CCF2 emitted a green fluorescence (cells infected with $\Delta$ escN mutant expressing TccP2-TEM).

Phalloidin staining and quantification of the efficiency of pedestal formation (see Methods) revealed that EDL933 was able to induce actin accretion during infection of an Nck1-/ Nck2 - fibroblast cell line, at a similar efficiency to infection of a control Nck $1+/ \mathrm{Nck} 2+$ fibroblast cell line (Fig. 3b). In agreement with Campellone \& Leong, 2005, strain E2348/69 induced less intense actin accretion at significantly reduced frequency in Nck1-/Nck2- fibroblast cells in comparison to $\mathrm{Nck} 1+/ \mathrm{Nck} 2+$ cells $(P<0.05)$, when preactivated by static growth in tissue-culture medium and $5 \% \mathrm{CO}_{2}$ (Fig. 3b). The residual and inefficient ability of EPEC E2348/69 to trigger actin polymerization is likely to be due to a recently identified Nck-independent pathway mediated by unknown cellular or bacterial factors (Campellone \& Leong, 2005). In contrast, in a similar manner to TccP-expressing EPEC O119 : H6 strain ICC199 and EHEC O157 : H7 strain
EDL933, TccP2-expressing B171 was able to trigger actin polymerization during infection of an Nck1-/Nck2fibroblast cell line, at a similar efficiency as during infection of an Nck1 + /Nck2 + fibroblast cell line (Fig. 3b). Thus, it appears that B171 is able to utilize an Nck-independent pathway to efficiently induce actin polymerization upon infection.

\section{Functional analysis of TccP2}

In order to elucidate the function of TccP2, we carried out infections of Nck1-/Nck2- fibroblast cell lines with EPEC 1 E2348/69 expressing tccP2_B171 (pICC365). Phalloidin staining and quantification of efficiency of pedestal formation revealed that expression of tccP2 in E2348/69 significantly enhanced its ability to trigger actin polymerization in Nck1-/Nck2- cells (Fig. 4a), suggesting that translocated TccP2 is able to promote host-cell actin polymerization under adherent E2348/69 in the absence of a functional Tir(P)-Nck actin-remodelling pathway.

In order to determine the role of $t c c P 2$ in $\mathrm{B} 171$-induced $\mathrm{A} /$ $\mathrm{E}$ lesions, a non-polar deletion of tccP2 was generated, producing strain $\mathrm{B} 171 \Delta t c c P 2$ (ICC216). Infection of $\mathrm{HeLa}$ cells revealed that $\mathrm{B} 171 \Delta t c c P 2$ induced actin polymerization under attached bacteria in a similar manner to wildtype B171 (Fig. 4b), despite exhibiting reduced cell adherence (B171 $\Delta t c c P 2$ adhered to $48 \pm 13 \%$ of cells; in comparison, wild-type B171 adhered to $99.5 \pm 1 \%$ of cells). However, B171 $\Delta t c c P 2$ was unable to trigger actin polymerization beneath adherent bacteria during infection of Nck1-/Nck2- fibroblasts (Fig. 4c). Similar to published observations regarding inefficiency of binding and effector translocation into Nck-deficient MEF cell lines (Campellone et al., 2004a), B171 $\Delta t c c P 2$ interacted with Nck-deficient fibroblasts at levels too low to allow strict quantification of pedestal formation. The ability of $\mathrm{B} 171 \Delta t c c P 2$ to trigger actin accretion was completely restored by introduction of plasmids encoding TccP_EDL933 (pICC281) (Fig. 4c) and TccP2_B171 (pICC365) (data not shown). These results suggest that B171, similar to EHEC $\mathrm{O} 157$, is able to trigger localized actin polymerization in an Nck-independent and TccP-dependent manner. Significantly though, B171 is different from EHEC O157, as it can also trigger actin polymerization via a TccP-independent mechanism.

In order to determine whether both the Nck pathway and the TccP pathway are activated at the site of bacterial attachment, pICC365 encoding C-terminal HA-tagged TccP2_B171 was introduced into B171. Co-immunostaining with HA and Nck antibodies revealed that Nck and TccP2 were simultaneously concentrated in actin-rich pedestals beneath adherent bacteria (Fig. 5a), indicating that B171 has the ability to simultaneously utilize the Nck- and TccP2-mediated actin-remodelling pathways. To confirm that TccP2 functions upstream of N-WASP in the actinpolymerization cascade, we infected an N-WASPdeficient fibroblast cell line (N-WASP ${ }^{-/-}$MEFs with 
(a)

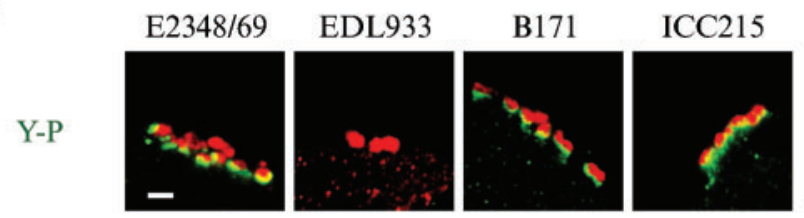

(b)

\section{Nck1-/Nck2-fibroblasts}

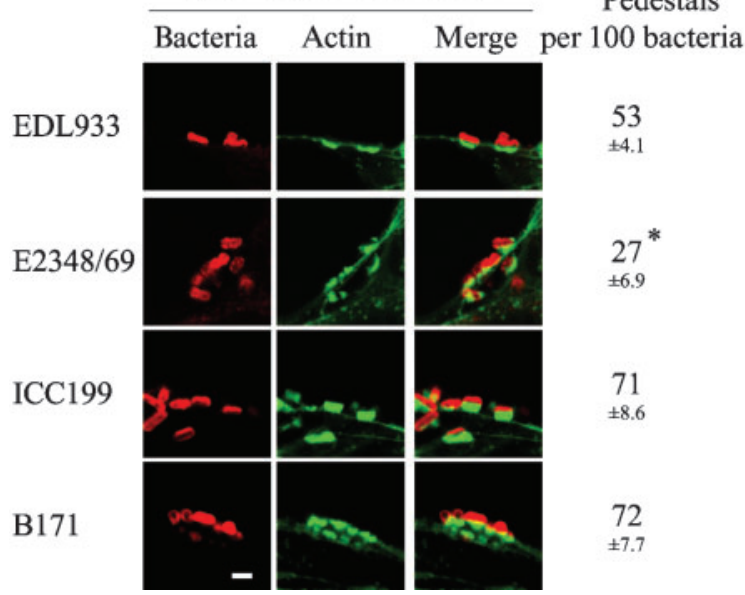

Nck1+/Nck2+fibroblasts

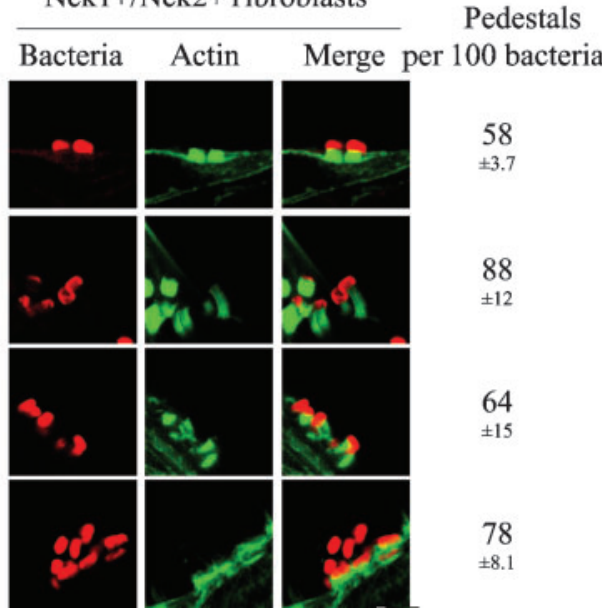

Fig. 3. (a) Widespread $\operatorname{Tir}_{(\mathrm{Y}-\mathrm{P})}$, labelled in green, was observed at the site of bacterial adhesion after infection of HeLa cells with strains E2348/69, B171 and ICC215, but not with EDL933. Bar, $2 \mu \mathrm{m}$. (b) FAS. EDL933, ICC199 and B171, but not E2348/69, triggered efficient actin polymerization following infection of Nck1-/Nck2- fibroblasts. All strains tested, including E2348/69, efficiently induced actin polymerization in infected Nck1+/Nck2 + fibroblasts. The asterisk indicates a statistically significant difference in the percentage of pedestals triggered on Nck1-/Nck2- fibroblasts, compared to that triggered on Nck1+/Nck2 + fibroblasts by EPEC E2348/69 $(P<0.05)$. Bacteria, labelled in red, were detected with anti-intimin or antiEHEC antibodies for EPEC E2348/69, ICC199 and B171 strains, and EHEC EDL933, respectively. Actin was labelled in green with Oregon Green-conjugated phalloidin. Bar, $2 \mu \mathrm{m}$.

B171 $t c c P 2($ pICC365) (expressing HA-tagged TccP2). Coimmunostaining of infected cells with $\operatorname{Tir}_{\mathrm{EPEC}}$ antiserum and HA antibodies revealed that both Tir and TccP2-HA were recruited to the site of bacterial attachment in the absence of N-WASP (Fig. 5b). As expected, no TccP-HA was detected beneath $\mathrm{B} 171 \Delta t c c P 2$ (data not shown), and neither strain was able to trigger formation of actin pedestals on $\mathrm{N}$-WASP ${ }^{-/-}$MEFs. Infection and immunostaining of control N-WASP-proficient cells $\left(\mathrm{N}-\mathrm{WASP} \mathrm{P}^{+/+}\right.$ MEFs) revealed that Tir and $\mathrm{TccP} 2$ were recruited to sites of adherent $\mathrm{B} 171 \Delta t c c \mathrm{P} 2$ expressing HA-tagged TccP2, but crucially, actin pedestals were triggered. Taken together, these data show that TccP2 is recruited in the absence of $\mathrm{N}$ WASP, and suggest that N-WASP is not required for the indirect interaction between Tir and TccP2, and that $\mathrm{N}$ WASP is a critical factor in the B171-induced actinpolymerization cascade.

\section{Recruitment of TccP2 and Nck during infection of human intestinal biopsy samples with B171}

To investigate the role of TccP2 during IVOC, paediatric small intestinal biopsy samples were infected with strain
$\mathrm{B} 171$ and its isogenic tccP2 mutant (B171 $\Delta t c c P 2)$. As shown in Fig. 6, both wild-type and deletion mutant attached intimately to human intestinal mucosa, causing microvillus elongation in between adhering bacteria. Immunofluorescence staining of cryosectioned organculture samples showed that TccP2 was translocated into human intestinal epithelium and localized beneath adherent B171 bacteria. The host adaptor protein Nck was recruited by both wild-type and $\mathrm{B} 171 \Delta t c c P 2$ bacteria; in contrast, and as expected, no TccP2 staining was observed in B171 $t$ tccP2-infected samples (Fig. 7).

\section{tccP and tccP2 are functionally interchangeable}

Considering that $\mathrm{TccP}_{-\mathrm{ICC} 199}$ was $77 \%$ identical to TccP2_B171 and that TccP_EDL933 complemented $\mathrm{B} 171 \Delta t c c P 2$ (Fig. 4c), we carried out a reciprocal experiment to determine the ability of TccP2 to complement an EDL933 $\Delta t c c P$ mutant strain. To this end, $t c c P 2$ from strains B171 (consisting of four PRRs) and ICC215 (consisting of six PRRs), cloned under the control of an IPTG-inducible promoter and tagged with a C-terminal HA epitope (pICC365 and pICC366, respectively), was introduced into 
(a)

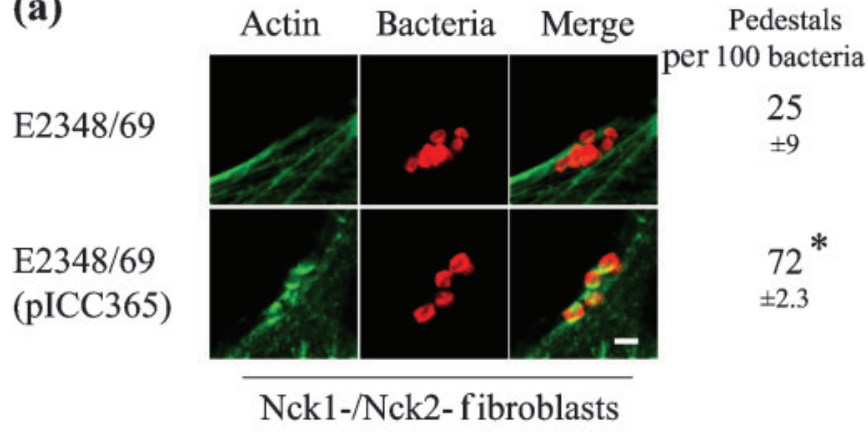

(b)

B171

$\mathrm{B} 171 \Delta t c c P 2$
Pedestals per 100 bacteria 89 $\pm 5.5$ 86 $\pm 9.1$ (c)

B171
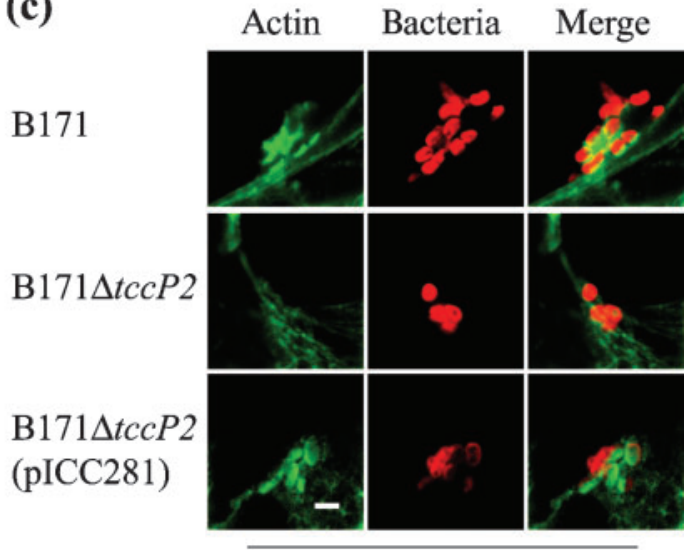

Nck1-/Nck2-fibroblasts

HeLa cells

Fig. 4. (a) Nck1-/Nck2- fibroblasts were infected with $t c c P^{-} /$tccP2 $2^{-}$EPEC 1 strain E2348/69 and E2348/69(plCC365tccP2_B171). Expression of TccP2_B171 compensated for the absence of Nck, enabling efficient and significantly different $(P<0.05)$ production of actin-rich pedestals at the site of bacterial attachment. Bar, $2 \mu \mathrm{m}$. (b) B171 and its isogenic B171 ttccP2 mutant strain induced actin polymerization at a similar efficiency in infected HeLa cells. Bar, $2 \mu \mathrm{m}$. (c) Efficient actin polymerization was detected following infection of Nck1-/Nck2- fibroblasts with B171, but not with B171 $\Delta t c c P 2$. Wildtype phenotype was restored by complementation of $\mathrm{B} 171 \Delta t c c P 2$ with plCC281 (tccP) or plCC365 (tccP2) (data not shown). Bacteria, labelled in red, were detected with anti-intimin $\beta$ or anti-intimin $\alpha$ antibodies for B171 and E2348/69, respectively. Actin was labelled in green with phalloidin-Oregon Green. Bar, $2 \mu \mathrm{m}$.

strain ICC185 (EDL933 $\Delta t c c P$ ). The ability to complement the $t c c P$ mutation and induce actin-pedestal assembly during infection was analysed by immunofluorescence. Phalloidin staining revealed that $t c c P 2_{-B 171}$ and $t c c P 2$ ICC215 complemented the ability of EDL933 $\Delta t c c P$ to generate $\mathrm{A} / \mathrm{E}$ lesions following infection of HeLa cells (Fig. 8). Co-staining of infected HeLa cells with an anti-HA $\mathrm{mAb}$ and phalloidin revealed that TccP2-HA was detected beneath ICC185(pICC365) and ICC185(pICC366) bacteria, co-localizing with F-actin at the tip of the pedestals (Fig. 8). In contrast, introduction of a plasmid-borne copy of $Z 1385$ (pseudo tccP2 allele of EDL933) did not restore the ability of ICC185 to induce actin pedestals (data not shown). These data indicate that $t c c P 2$ encodes a protein that can functionally substitute for TccP_EDL933, and that both $t c c P$ homologues, $t c c P$ and $t c c P 2$, are functionally interchangeable.

\section{DISCUSSION}

Until recently, the prevalent dogma concerning EPEC- and EHEC-triggered localized actin polymerization, based on studies of two prototypical strains (O127 : H6 EPEC 1 strain E2348/69 and O157 : H7 EHEC strain EDL933), was that formation of actin-rich pedestals is achieved via distinct signal-transduction pathways. A C-terminal 12 aa motif (including phosphorylated Y474) of $\operatorname{Tir}_{\text {EPEC }}$ binds Nck, which in turn recruits and activates N-WASP beneath adherent bacteria (Campellone et al., 2004b). N-WASP then recruits the Arp2/3 complex, leading to the generation of a network of actin filaments under attached bacteria. In contrast, a different C-terminal 12 aa motif of Tir EHEC_O157 (encompassing Y458) (Campellone et al., 2006; AllenVercoe et al., 2006) clusters TccP, which leads to the formation of actin-rich pedestals by an Nck-independent mechanism (Gruenheid et al., 2001). However, through the analysis of a large number of clinical and environmental non-O157 EHEC and EPEC isolates, we have identified a subset of strains that have the potential to induce actin polymerization in the host eukaryotic cell by simultaneously utilizing the Tir(P)-Nck and Tir-TccP pathways (Garmendia et al., 2005). The predominant EPEC group in this category are strains belonging to EPEC serotype O119 : H6 (Whale et al., 2006), which is situated in the evolutionary tree in between the EPEC 1 and EPEC 2 lineages (Whittam \& McGraw, 1996). 
(a)
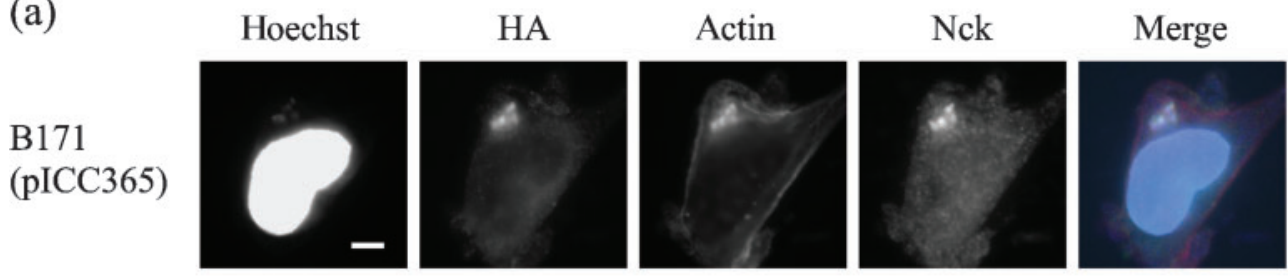

(b)

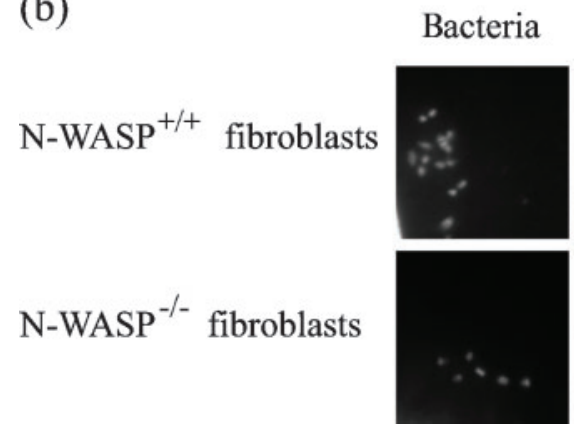

Tir

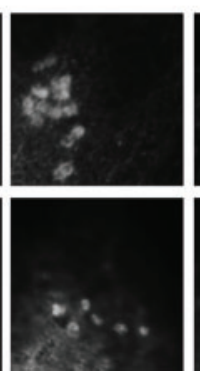

HA
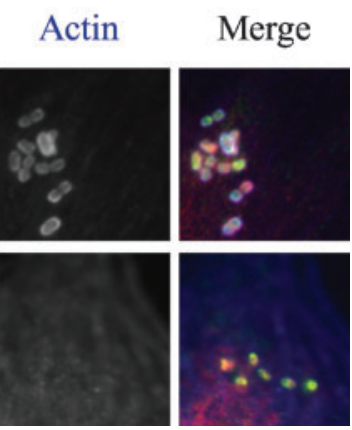

Fig. 5. (a) Nck and TccP2 were simultaneously recruited and co-localized at the site of strain B171(plCC365-tccP2_B171)induced actin assembly beneath adherent bacteria during infection of HeLa cells. Nck was labelled in green using an anti-Nck antibody, TccP2-HA was labelled in far red with an anti-HA mAb, and actin was labelled in red, using rhodamine-conjugated phalloidin. Bacteria and cell nuclei were visualized with Hoechst stain (blue). Separate monochrome images of the UV, far-red, red and green fluorescence channels are shown, as well as merged images of all channels (right column). Bar, $10 \mu \mathrm{m}$. (b) Tir and TccP2 co-localized at the site of B171 $t$ tccP2(plCC365-tccP2_B171) attachment during infection of N-WASP ${ }^{+/+}$and N$\mathrm{WASP}^{-1-}$ fibroblasts. However, induced actin assembly was only detected beneath adherent bacteria during infection of $\mathrm{N}$ $\mathrm{WASP}^{+/+}$fibroblasts. Tir was labelled in red, TccP2-HA was labelled in green, and actin was labelled in far red (shown in blue). Bacteria were visualized with Hoechst stain (shown in monochrome).

EPEC 1 strains are characterized by expression of flagellar antigens H6 or H34 (Whittam et al., 1993), possession of a complete tra region (Brinkley et al., 2006), and intimin $\alpha$. In this study, we have shown that other characteristics of EPEC 1 strains are expression of $\operatorname{Tir}_{(\mathrm{Y}-\mathrm{P})}$ and lack of $t c c P$ and $t c c P 2$. Importantly, strains belonging to $\mathrm{O} 119$ : $\mathrm{H} 6$ are unique, as they do not belong to EPEC 1 (Whittam \& McGraw, 1996), express intimin type $\beta$ (Adu-Bobie et al., 1998), almost harbour tccP (Garmendia et al., 2005), and may have a complete tra region (Brinkley et al., 2006).
These characteristics suggest that the evolution of this serotype followed a distinct path, through which it acquired virulence determinants horizontally. The EPEC 2 lineage is characterized by expression of flagellar antigens $\mathrm{H} 2$ or $\mathrm{H}-$ (Whittam et al., 1993), intimin $\beta$ (Adu-Bobie et al., 1998) and $\operatorname{Tir}_{(\mathrm{Y}-\mathrm{P})}$. Unexpectedly, we found that with the exception of only one isolate, all of the EPEC 2 strains tested contained intact $t c c P 2$. Sequence analysis of TccP2 from different isolates showed that, other than variation in the number of PRRs, the protein sequences were identical.
Non-infected

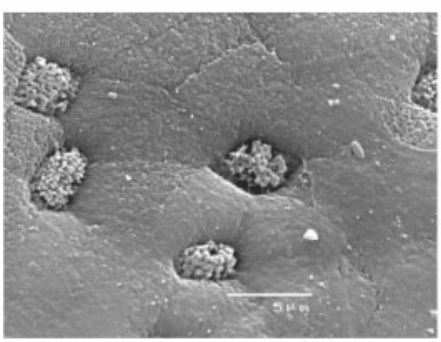

B171

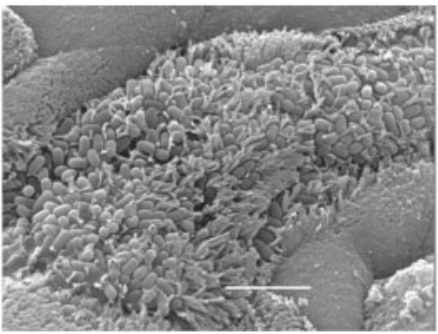

B171 $\Delta t c c P 2$

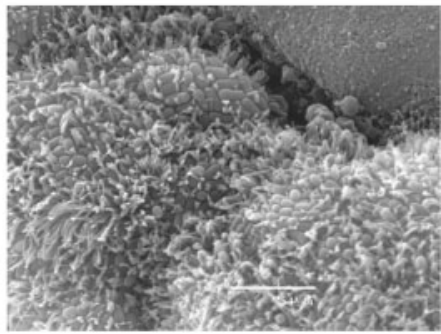

Fig. 6. Both wild-type and $\triangle t c c P 2 B 171$ strains induced A/E lesions in intestinal IVOC. Scanning electron micrographs of duodenal mucosa infected with $\mathrm{B} 171$ and $\mathrm{B} 171 \Delta t c \mathrm{P} 2$ are shown. A non-infected sample was included as a negative control. Bars, $5 \mu \mathrm{m}$. 

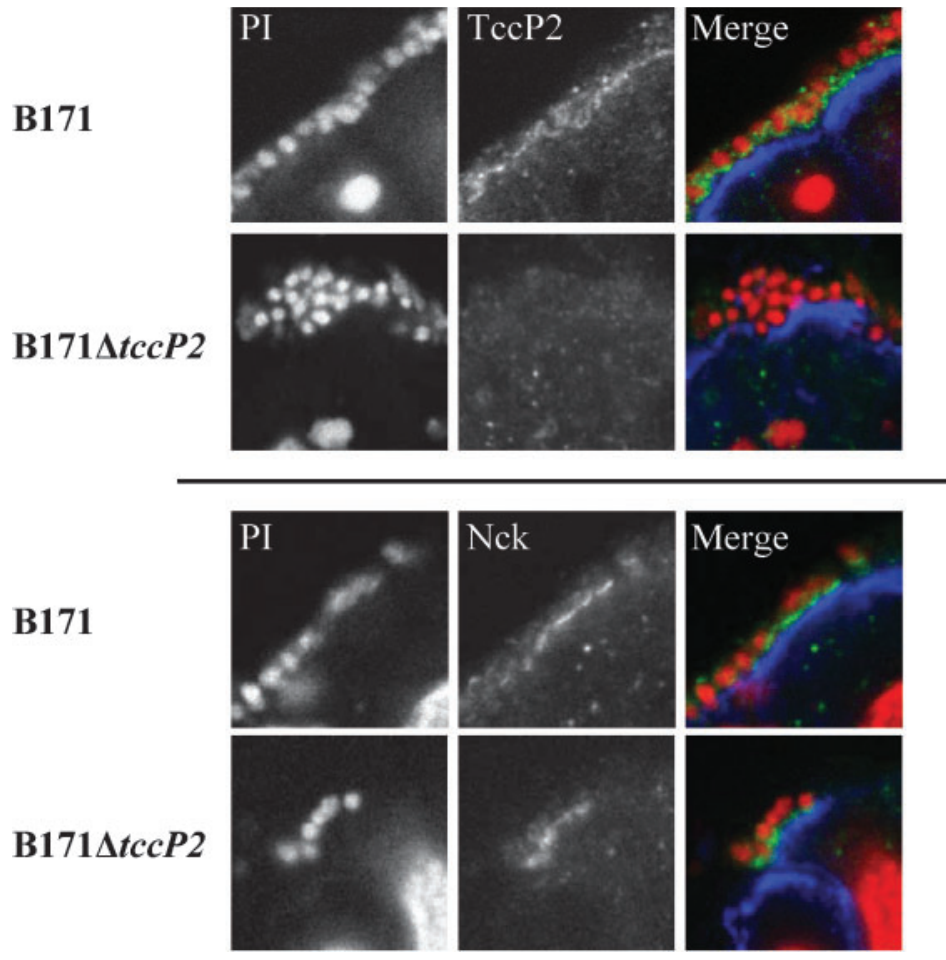

Fig. 7. Nck was recruited to the site of IVOC adhesion of strains $\mathrm{B} 171$ and $\mathrm{B} 171 \Delta t c \mathrm{P} P 2$, while TccP2 was found only under adherent B171. Terminal ileal mucosa was infected with $\mathrm{B} 171$ and B171 $\Delta t c c P 2$ for $8 \mathrm{~h}$, and cryosections were processed for immunofluorescence. Staining was performed for TccP2 (green in merged image, upper two panels) or Nck (green, lower two panels). Bacteria and cell nuclei were visualized by propidium iodide $(\mathrm{PI})$ stain (red). Epithelial cells were counterstained with anti-cytokeratin (labelled blue). Separate monochrome images of the red and green fluorescence channels (left and middle column respectively) are shown, as well as merged images of all channels (right column).
The identification of TccP2 in prototypic EPEC strain $\mathrm{B} 171$ highlights the fortuitous nature of studying pathogenesis in prototypical strains, as the commonly used E2348/69,

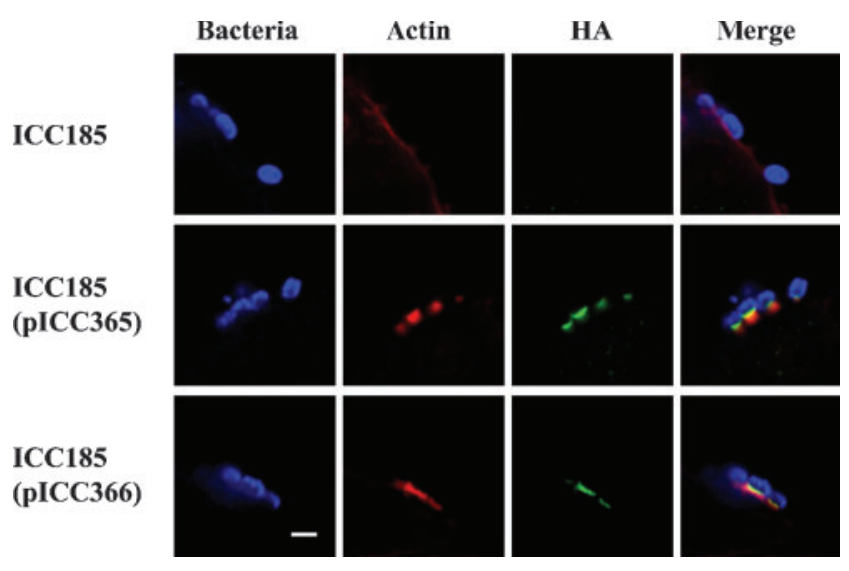

Fig. 8. FAS and recruitment of TccP2 to the site of bacterial adhesion. HeLa cells were infected with strain EDL933 $\Delta t c c P$ for $5 \mathrm{~h}$. Following fixation and permeabilization, bacteria were labelled in blue. Actin was detected by rhodamine-phalloidin, and TccP2$\mathrm{HA}$ was labelled in green. Strain ICC185, unable to form actin-rich pedestals during infection, was complemented by both TccP2_B171 (plCC365) and TccP2_ıcc215 (plCC366). TccP2 was detected beneath adherent ICC185(pICC365) and ICC185(pICC366), but not ICC185, and co-localized with polymerized actin at the tip of the triggered actin pedestal. Bar, $2 \mu \mathrm{m}$. which is tccP- and tccP2-negative, allowed the identification of the role of Nck in A/E lesion formation.

Using $\mathrm{B} 171$ as a representative of EPEC 2 tccP2-expressing strains, we have shown that TccP2 is a T3SS-translocated effector involved in triggering actin remodelling during infection. In a similar manner to tccP-positive EPEC and EHEC strains, but in contrast to prototypical EPEC 1 strains, B171 was able to efficiently trigger Nck-independent actin polymerization, an activity dependent on $t c c P 2$. Due to the high level of sequence conservation between TccP and TccP2, we observed functional redundancy between the two TccP homologues: TccP2 was able to restore actin-polymerization ability to EDL933 $\Delta t c c P$ during infection of HeLa cells, and TccP was able to complement $\mathrm{B} 171 \Delta t c c \mathrm{P} 2$ for triggering actin remodelling during infection of Nck1-/Nck2- fibroblasts. Nevertheless, due to the difference between the $\mathrm{N}$ termini of TccP and TccP2, we cannot exclude the possibility of subtle functional differences.

In a similar way to TccP-positive EPEC strains, TccP2 is localized at the tip of the pedestal and co-localizes with Nck during B171 infection of epithelial cells. Of note, $\operatorname{Tir}_{B 171}$ harbours both a Y474 equivalent in the context of a consensus Nck binding site, and a second tyrosine residue within a region that shares $75 \%$ amino acid identity with a motif responsible for $\mathrm{TccP} / \mathrm{EspF}_{\mathrm{U}}$ recruitment in $\mathrm{Tir}_{\mathrm{EHEC}}$ (Campellone et al. 2006). Moreover, both TccP2 and Nck are recruited to the site of B171 adhesion to human intestinal IVOC. In the absence of TccP2 (i.e. during infection with $\mathrm{B} 171 \Delta t c c P 2)$, Nck was still recruited, 


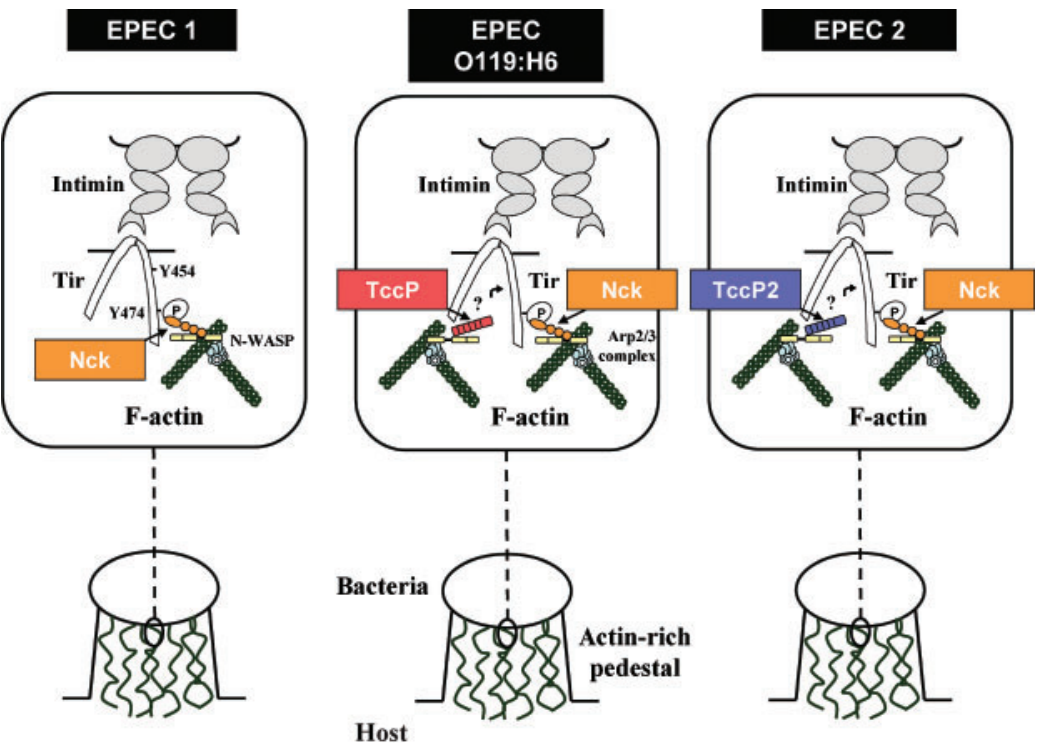

Fig. 9. Summary of actin-polymerization cascades induced by EPEC 1, EPEC 2 and EPEC O119 : H6. All EPEC lineages translocate Tir that once inserted into the host-cell membrane serves as a receptor for the bacterial adhesin intimin. Intimin-mediated clustering of Tir triggers phosphorylation of tyrosine residue Y474 and concurrent recruitment of Nck. Nck recruits and activates N-WASP, leading to Arp2/3-dependent actin polymerization and pedestal formation. EPEC 2 and 'non-1 non2 lineage' O119 : H6 EPEC, but not EPEC 1 bacteria, also translocate TccP2 and TccP, respectively, and are capable of recruiting $\mathrm{N}$ WASP directly and triggering Nck-independent actin-pedestal formation. Note that TccP does not bind Tir directly, but via an unidentified host-encoded adaptor (indicated by a question mark).

suggesting that recruitment of Nck, bacterial adhesion and $\mathrm{A} / \mathrm{E}$ lesion formation are not dependent on TccP2. A model describing the actin-polymerization cascades induced by EPEC 1, EPEC 2 and 'non-1 non-2' EPEC O119: H6 is shown in Fig. 9. The ability of strains belonging to EPEC 2 to trigger actin polymerization using apparently redundant mechanisms raises intriguing questions regarding the possible spatial and temporal specificities of their function.

We have shown that possession of $t c c P 2$ and $\operatorname{Tir}_{(\mathrm{Y}-\mathrm{P})}$ is a characteristic of EPEC 2. This observation raises some interesting questions, including whether or not the ability to use both the Nck and TccP2 pathways confers an advantage upon EPEC 2, and if so, in which environments EPEC 2 strains are more virulent than EPEC 1 strains. Finally, strain E2348/69 (O127 : H7), which has been used worldwide as a prototype EPEC strain, harbours $\operatorname{Tir}_{(\mathrm{Y}-\mathrm{P})}$ but is tccP negative. As such, when studying actin-pedestal formation, E2348/69 should no longer be used as a general representative of typical EPEC; it should now only be considered representative of EPEC 1, while B171 should be used as a prototype strain representing the EPEC 2 lineage.

\section{ACKNOWLEDGEMENTS}

We thank Scott Snapper of Harvard Medical School for the N-WASP knockout and control MEF cell lines. We thank Dr Olivier Marches for helpful advice with the TEM-1 translocation assay. A. D. W. is supported by a Biotechnology and Biological Sciences Research Council PhD studentship. The work in the laboratory of T. A. T. G. was supported by a grant from Fundação de Amparo à Pesquisa do Estado de São Paulo (FAPESP); the work in the laboratory of T. H. was supported by grants from Grant-in-Aid for Scientific Research on Priority Areas 'Applied Genomics', the 21st Century COE Program (Life Science) from the Ministry of Education, Science and Technology of Japan, and by a Grant-in-Aid from the Ministry of Health, Labour and Welfare of Japan (H17-Sinkou-ippan-019); the work in the laboratory of A. D. P. was supported by the National
Insitutes of Health (grant R37AI21657 to James Kaper); and the work in the laboratory of G. F. was supported by a grant from the Wellcome Trust.

\section{REFERENCES}

Adu-Bobie, J., Frankel, G., Bain, C., Goncaleves, A. G., Trabulsi, L. R., Douce, G., Knutton, S. \& Dougan, G. (1998). Detection of intimin $\alpha$, $\beta, \gamma$, and $\delta$, four intimin derivatives expressed by attaching and effacing microbial pathogens. J Clin Microbiol 36, 662-668.

Allen-Vercoe, E., Waddell, B., Toh, M. C. \& Devinney, R. (2006). Amino acid residues within EHEC O157:H7 Tir involved in phosphorylation, $\alpha$-actinin recruitment and Nck-independent pedestal formation. Infect Immun 74, 6196-6205.

Baldini, M. M., Kaper, J. B., Levine, M. M., Candy, D. C. \& Moon, H. W. (1983). Plasmid-mediated adhesion in enteropathogenic Escherichia coli. J Pediatr Gastroenterol Nutr 2, 534-538.

Brinkley, C., Burland, V., Keller, R., Rose, D. J., Boutin, A. T., Klink, S. A., Blattner, F. R. \& Kaper, J. B. (2006). Nucleotide sequence analysis of the enteropathogenic Escherichia coli adherence factor plasmid pMAR7. Infect Immun 74, 5408-5413.

Campellone, K. G. \& Leong, J. M. (2005). Nck-independent actin assembly is mediated by two phosphorylated tyrosines within enteropathogenic Escherichia coli Tir. Mol Microbiol 56, 416-432.

Campellone, K. G., Giese, A., Tipper, D. J. \& Leong, J. M. (2002). A tyrosine-phosphorylated 12-amino-acid sequence of enteropathogenic Escherichia coli Tir binds the host adaptor protein Nck and is required for Nck localization to actin pedestals. Mol Microbiol 43, 1227-1241.

Campellone, K. G., Robbins, D. \& Leong, J. M. (2004a). EspF $F_{U}$ is a translocated EHEC effector that interacts with Tir and N-WASP and promotes Nck-independent actin assembly. Dev Cell 7, 217-228.

Campellone, K. G., Rankin, S., Pawson, T., Kirschner, M. W., Tipper, D. J. \& Leong, J. M. (2004b). Clustering of Nck by a 12-residue Tir phosphopeptide is sufficient to trigger localized actin assembly. J Cell Biol 164, 407-416.

Campellone, K. G., Brady, M. J., Alamares, J. G., Rowe, D. C., Skehan, B. M., Tipper, D. J. \& Leong, J. M. (2006). Enterohaemorrhagic 
Escherichia coli Tir requires a C-terminal 12-residue peptide to initiate EspF $_{\mathrm{U}}$-mediated actin assembly and harbours $\mathrm{N}$-terminal sequences that influence pedestal length. Cell Microbiol 8, 1488-1503.

Charpentier, X. \& Oswald, E. (2004). Analysis of type III translocation signals of enteropathogenic and enterohemorrhagic Escherichia coli effectors using TEM-1 beta-lactamase as a fluorescence-based reporter. J Bacteriol 186, 5486-5495.

Chen, H. D. \& Frankel, G. (2005). Enteropathogenic Escherichia coli: unravelling pathogenesis. FEMS Microbiol Rev 29, 83-98.

Datsenko, K. A. \& Wanner, B. L. (2000). One-step inactivation of chromosomal genes in Escherichia coli K12 using PCR products. Proc Natl Acad Sci U S A 97, 6640-6645.

Frankel, G., Phillips, A. D., Trabulsi, L. R., Knutton, S., Dougan, G. \& Matthews, S. J. (2001). Intimin and the host cell - is it bound to end in $\operatorname{Tir}(\mathrm{s})$ ? Trends Microbiol 9, 214-218.

Garmendia, J., Phillips, A., Chong, Y., Schuller, S., Marches, O., Dahan, S., Oswald, E., Shaw, R. K., Knutton, S. \& Frankel, G. (2004). TccP is an enterohaemorrhagic E. coli O157 : H7 type III effector protein that couples Tir to the actin-cytoskeleton. Cell Microbiol 6, 1167-1183.

Garmendia, J., Ren, Z., Tennant, S., Vieira, M. A. M., Chong, Y., Whale, A., Azzopardi, K., Dahan, S., Palma Sircili, M. \& other authors (2005). Distribution of $t c c P$ in clinical enterohaemorrhagic and enteropathogenic Escherichia coli isolates. J Clin Microbiol 43, 5715-5720.

Garmendia, J., Carlier, M. F., Egile, C., Didry, D. \& Frankel, G. (2006). Characterisation of TccP-mediated N-WASP activation during enterohaemorrhagic Escherichia coli infection. Cell Microbiol 8, 1444-1455.

Girón, J. A., Ho, A. S. \& Schoolnik, G. K. (1991). An inducible bundleforming pilus of enteropathogenic Escherichia coli. Science 254, 710-713.

Goosney, D. L., DeVinney, R. \& Finlay, B. B. (2001). Recruitment of cytoskeletal and signaling proteins to enteropathogenic and enterohemorrhagic Escherichia coli pedestals. Infect Immun 69, 3315-3322.

Gruenheid, S., DeVinney, R., Bladt, F., Goosney, D., Gelkop, S., Gish, G. D., Pawson, T. \& Finlay, B. B. (2001). Enteropathogenic E. coli Tir binds Nck to initiate actin pedestal formation in host cells. Nat Cell Biol 3, 856-859.

Hartland, E. L., Batchelor, M., Delahay, R. M., Hale, C., Matthews, S., Dougan, G., Knutton, S., Connerton, I. \& Frankel, G. (1999). Binding of intimin from enteropathogenic Escherichia coli to Tir and to host cells. Mol Microbiol 32, 151-158.

Hicks, S., Frankel, G., Kaper, J. B., Dougan, G. \& Phillips, A. D. (1998). Role of intimin and bundle-foming pili in enteropathgenic Escherichia coli adhesion to pediatric intestine in vitro. Infect Immun 66, 1570-1578.

Jarvis, K. G., Girón, J. A., Jerse, A. E., McDaniel, T. K., Donnenberg, M. S. \& Kaper, J. B. (1995). Enteropathogenic Escherichia coli contains a putative type III secretion system necessary for the export of proteins involved in attaching and effacing lesion formation. Proc Natl Acad Sci U S A 92, 7996-8000.

Jerse, A. E., Yu, J., Tall, B. D. \& Kaper, J. B. (1990). A genetic locus of enteropathogenic Escherichia coli necessary for the production of attaching and effacing lesions on tissue culture cells. Proc Natl Acad Sci U S A 87, 7839-7843.

Kaper, J. B. (1996). Defining EPEC. Rev Microbiol (Suppl. 1) 27, 130-133.

Karch, H., Tarr, P. I. \& Bielaszewska, M. (2005). Enterohaemorrhagic Escherichia coli in human medicine. Int J Med Microbiol 295, 405-418.
Kenny, B., DeVinney, R., Stein, M., Reinscheid, D. J., Frey, E. A. \& Finlay, B. B. (1997). Enteropathogenic E. coli (EPEC) transfers its receptor for intimate adherence into mammalian cells. Cell 91, 511-520.

Knutton, S., Lloyd, D. R. \& McNeish, A. S. (1987). Adhesion of enteropathogenic Escherichia coli to human intestinal enterocytes and cultured human intestinal mucosa. Infect Immun 55, 69-77.

Levine, M. M., Berquist, E. J., Nalin, D. R., Waterman, D. H., Hornick, R. B., Young, C. R. \& Rowe, B. (1978). Escherichia coli that cause diarrhoea but do not produce heat-labile or heat-stable enterotoxins and are non-invasive. Lancet 1, 1119-1122.

Lommel, S., Benesch, S., Rottner, K., Franz, T., Wehland, J. \& Kuhn, R. (2001). Actin pedestal formation by enteropathogenic Escherichia coli and intracellular motility of Shigella flexneri are abolished in NWASP-defective cells. EMBO Rep 2, 850-857.

McDaniel, T. K., Jarvis, K. G., Donnenberg, M. S. \& Kaper, J. B. (1995). A genetic locus of enterocyte effacement conserved among diverse enterobacterial pathogens. Proc Natl Acad Sci U S A 92, 1664-1668.

Mellies, J. L., Elliott, S. J., Sperandio, V., Donnenberg, M. S. \& Kaper, J. B. (1999). The Per regulon of enteropathogenic Escherichia coli: identification of a regulatory cascade and a novel transcriptional activator, the locus of enterocyte effacement (LEE)-encoded regulator (Ler). Mol Microbiol 33, 296-306.

Ogura, Y., Ooka, T., Whale, A., Garmendia, J., Beutin, L., Tennant, S., Krause, G., Morabito, S., Chinen, I. \& other authors (2007). TccP2 of O157:H7 and non-O157 enterohemorrhagic Escherichia coli (EHEC): challenging the dogma of EHEC-induced actin polymerisation. Infect Immun 75, 604-612.

Orskov, F., Whittam, T. S., Cravioto, A. \& Orskov, I. (1990). Clonal relationships among classic enteropathogenic Escherichia coli (EPEC) belong to different $\mathrm{O}$ groups. J Infect Dis 162, 76-81.

Phillips, N., Hayward, R. D. \& Koronakis, V. (2004). Phosphorylation of the enteropathogenic E. coli receptor by the Src-family kinase c-Fyn triggers actin pedestal formation. Nat Cell Biol 6, 618-625.

Riley, L. W., Junio, L. N., Libaek, L. B. \& Schoolnik, G. K. (1987). Plasmid-encoded expression of lipopolysaccharide O-antigenic polysaccharide in enteropathogenic Escherichia coli. Infect Immun 55, 2052-2056.

Schlosser-Silverman, E., Elgrably-Weiss, M., Rosenshine, I., Kohen, R. \& Altuvia, S. (2000). Characterization of Escherichia coli DNA lesions generated within J774 macrophages. J Bacteriol 182, 5225-5230.

Swimm, A., Bommarius, B., Li, Y., Cheng, D., Reeves, P., Sherman, M., Veach, D., Bornmann, W. \& Kalman, D. (2004). Enteropathogenic Escherichia coli use redundant tyrosine kinases to form actin pedestals. Mol Biol Cell 15, 3520-3529.

Trabulsi, L. R., Keller, R. \& Gomes, T. A. (2002). Typical and atypical enteropathogenic Escherichia coli. Emerg Infect Dis 8, 508-513.

Whale, A. D., Garmendia, J., Gomes, T. A. \& Frankel, G. (2006). A novel category of enteropathogenic E. coli simultaneously utilises the Nck and TccP pathways to induce actin remodelling. Cell Microbiol 8, 999-1008.

Whittam, T. S. \& McGraw, E. A. (1996). Clonal analysis of EPEC serogroups. Rev Microbiol (Suppl. 1) 27, 7-16.

Whittam, T. S., Wolfe, M. L., Wachsmuth, I. K., Orskov, F., Orskov, I. \& Wilson, R. A. (1993). Clonal relationships among Escherichia coli strains that cause hemorrhagic colitis and infantile diarrhea. Infect Immun 61, 1619-1629.

Edited by: P. H. Everest 